\title{
Coisas do Brasil
}

\section{[ Brazilian matters}

\section{Marcelo Maraninchi ${ }^{1}$}

[ANDRADE, Mário de. Aspectos do folclore brasileiro. Coordenação de Telê Ancona Lopez. Estabelecimento do texto, apresentação e notas de Angela Teodoro Grillo (Global Editora, 20I9).

RESUMO - Aspectos do folclore brasileiro reafirma o interesse fecundo de Mário de Andrade (I893-I945) pelas manifestações do povo. No livro inédito, conteúdo e expressão se afinam para reconhecer o folclore como um "processo de conhecimento" e postular uma ética do trabalho intelectual. • PALAVRASCHAVE • Mário de Andrade; folclore brasileiro.
- ABSTRACT - Aspects of Brazilian folklore reaffirms the fruitful interest of Mário de Andrade (I893-I945) in popular manifestations. Content and expression come together in this unpublished book to regard folklore as a "process of knowledge" and postulate an ethics for the intellectual work. - KEYWORDS - Mário de Andrade; Brazilian folklore.

Recebido em 5 de dezembro de 2019

Aprovado em 28 de janeiro de 2020

MARANINCHI, Marcelo. Coisas do Brasil. Revista do Instituto de Estudos Brasileiros, Brasil, n. 75, p. I85-I9I, abr. 2020.

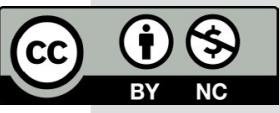

DOI: http://dx.doi.org/Io.II606/issn.23I6-9oIX.voi75pI85-I9I

I Universidade de São Paulo (USP, São Paulo, SP, Brasil). 
Quem topa com a discussão de Mário de Andrade em torno da origem brasileira do fado sente de imediato a mistura da pesquisa folclórica com o trabalho literário. As "Nótulas folclóricas", entre as quais o texto sobre o fado, significam mais um ponto de convergência entre os dois campos; reforçam o que Florestan Fernandes sublinhou como traço forte do escritor modernista ${ }^{2}$. Nelas, o estilo não recalca o eu do pesquisador, o desejo insatisfeito de conhecer, como também a habilidade no manejo da expressão. Ao abrir o texto, ele balbucia: "Coisa estranha...”. A certeza precária de que o fado nasceu no Brasil provinha de um registro estatístico sobre Portugal e Algarve, de I822, onde aquele consta como dança popular brasileira (BALBI, I822); em Portugal, sua documentação era posterior, de I849. Diante da republicação de um glossário de expressões portuguesas e brasileiras, também do século XIX, Mário de Andrade se inquieta e trata o caso como "bastante esquisito". É que o fado aparece no "trabalhinho" do visconde de Pedra Branca como expressão brasileira, correspondente ao francês bonderie. Só que bonderie, embora se pareça com o verbo bondir, saltar, não se encontra nos dicionários. Mário presume que se trata de um erro tipográfico, que o " $n$ " seria "u", e o fado poderia ser definido como bouderie: arrufo, briguinha sem consequência, algo similar a enfado. Pra complicar a questão, "fadista" se traduz por fille publique, "mulher da vida”. Até aí nada de dança, e muito de especulação e fantasia não camufladas. O autor cogita que o visconde "tenha escutado chamar 'fadista' a uma ou várias mulheres visivelmente 'da vida' e imaginasse a sinonímia que registrou” (p. I22). O que lhe interessa é o processo semântico pelo qual o destino mau pode ter virado dança:

Ora que o fado-dança nasceu entre gente das classes inferiores, menos protegida pelo fatum, e mesmo especialmente dada a forrobodós, furdunços e forrós, está provado por toda a documentação existente. Imagino pois toda uma evolução, não propriamente semântica, mas que provocou como que a recriação da mesma voz. De "fado", destino mau, gente do Brasil fizeram a palavra "fadista" pra designar pelo menos

2 "É preciso não esquecer que o folclore domina - e até certo ponto marca profundamente - sua atividade polimórfica de poeta, contista, romancista, crítico e ensaísta; e constitui também o seu campo predileto de pesquisas e estudos especializados" (FERNANDES, I946). 
as malfadadas; e como estas fadistas dançassem duais numerosamente uma dança, imitada das coreografias dos negros escravos, mas não exatamente mais um batuque, samba ou lundum, dessas "fadistas" que não eram nem valsistas ainda nem mais sambistas, se tirou de novo o substantivo "fado" já tão conhecido desses coitados, pra designar a dança nova. E desta forma os que "cumpriam o fado", principiaram sendo os que "batiam o fado" também. Engenhoso. (p. I23).

O entremeado de incertezas e suposições mostra como pesquisa e imaginação são mobilizadas, sem a distância, que às vezes é também de classe, entre o intelectual e seu objeto de estudo. Em certos trechos, a pontuação confunde, como se o passo da dança quase se perdesse. A aliteração em fado-forró-furdunço-forrobodó tempera de libido o engenho do autor. A concordância - "gente do Brasil fizeram" - aturde o purismo letrado. O diminutivo disperso aproxima o "trabalhinho" do Visconde; simplifica a atitude do pesquisador ao chamar o próprio texto de "nótula"; torna humana e pintoresca a briguinha sem consequência que se pode indicar como "enfado". As interrogações são muitas - "Será erro já do original ou do linotipista transcritor da Revista de Língua Portuguesa?”; “Será isso mesmo?”; “E se o nosso prezado visconde já conhecesse a palavra 'fado’ como dança popular brasileira?” (p. I22). Do mesmo modo as modulações de cautela: "Parece mais que provável”; "que eu saiba”; "isto é pura fantasia minha”; "é possível”; "imagino pois”; "não sei se deveria dizer assim”; "será talvez preferível” (p. I22-I23). Mário joga com o erro tipográfico e se apropria do francês como se fosse coisa sua 3 . Longe de uma soma de pormenores, o estilo mostra o método e o valor do texto. O movimento - no qual refere documentos raros, investiga etimologias, se espanta - quase faz ouvir Macunaíma falando “Tem coisa!”.

Publicadas no rodapé da Folha da Manhã, as "Nótulas" formam um conjunto heterogêneo e fragmentário, dedicado a temas diversos: o aboio do gado, se é triste ou melancólico; a existência de Rudá como deus tupi (afinal, Couto de Magalhães se baseou em testemunho fiel?); o emprego de expressões corriqueiras, como "truta”, pra mentira, ou "bamba” pra sujeito de prestígio; as variações da mula sem cabeça. Mário de Andrade comenta a lenda indígena sobre as manchas da lua, o jogo do "grufim" nos velórios pobres de São Paulo, o canto da arara-canindé, corrigindo Rousseau, que o atribuía aos selvagens do Canadá. A atenção ao material folclórico, e àquilo que as palavras ensinam sobre a cultura, reflete-se no cuidado com que Angela Teodoro Grillo e Telê Ancona Lopez organizaram a publicação de Aspectos do folclore brasileiro. A edição inédita, que confirma o plano do autor, se deve a pesquisadoras dedicadas a retraçar os processos de criação do polígrafo modernista, e de instituições de pesquisa e financiamento que deram o suporte material ${ }^{4}$. Esse projeto coletivo e institucional faz lembrar a importância do respaldo público à pesquisa e à conservação dos acervos no país.

3 “[...] desse ínclito visconde que me faz bondir a imaginação e bouder a indecisão [...]” (p. I23).

4 Fruto do projeto temático Fapesp-IEB-FFLCH/USP, Estudo do processo de criação de Mário de Andrade nos manuscritos de seu arquivo, em sua correspondência, em sua marginália e em suas leituras (2007-20II), coordenado pela profa. Telê Porto Ancona Lopez. 


\section{ÉTICA E TRABALHO INTELECTUAL}

Ao planejar as Obras completas, em I943, Mário de Andrade prevê que o volume I3 receba o título Aspectos do folclore brasileiro, composto de três partes: "O folclore no Brasil", "Estudos sobre o negro" e as já comentadas "Nótulas". A história dos manuscritos e do propósito de montar um livro sobre o folclore é resgatada na apresentação de Angela Grillo. Dois ensaios buscam situá-lo em meio aos estudos do folclore e estudos africanos. Maria Laura Viveiros de Castro Cavalcanti ocupa-se da primeira tarefa; Lígia Fonseca Ferreira, da segunda. Ao fim, um dossiê lastreia a edição no arquivo do escritor; apresenta fac-símiles do manuscrito, com desenhos e notas de trabalho; transcreve o plano do então diretor do Departamento de Cultura para comemorar os 50 anos da Abolição na cidade de São Paulo, e sugestões ao ministro Capanema para as festividades na Capital Federal; traz ainda uma bibliografia com vistas aos "Estudos sobre o negro". A capa reproduz a aquarela do viajante Carlos Julião, Coroação da rainha negra na Festa de Reis.

"O folclore no Brasil", primeira parte, consiste em um levantamento sobre os estudos do populário. Destinava-se a um manual de estudos brasileiros coordenado por William Berrien e Rubens Borba de Moraes. Berrien, professor em Harvard, representava o Conselho Americano das Sociedades Eruditas, patrocinador da edição. Rubens Borba dirigia a Biblioteca Municipal de São Paulo e estava ligado à Organização das Nações Unidas (ONU) como subdiretor de Serviços Bibliotecários. A encomenda prestigiosa previa a publicação em inglês, como Handbook of Brazilian studies. A versão datiloscrita entregue aos organizadores foi finalizada em outubro de I942. Pela guerra o projeto sofreu atrasos e modificações: saiu em I949, em português.

A avaliação de Mário de Andrade na abertura e encerramento do texto é que "a situação dos estudos do Folclore no Brasil ainda não é boa" (p. 23; 47). O diagnóstico não destoa do restante da obra. Os encarregados de outras disciplinas também apontam lacunas nos estudos brasileiros sobre arte, música, etnologia etc. Do ponto de vista de Mário, não se tratava apenas de incompletude, havia critérios mais firmes por estabelecer, e uma disposição de pesquisa profissional, não pautada pelo critério de beleza. A cópia conservada no arquivo do escritor traz uma nota de próprio punho explicando duas mudanças na versão entregue aos organizadores:

Desta redação, pra ser publicada nos States, a pedido do Rubens e do Berrien, foram retirados os itens de critério de organização bibliográfica do fichário que estão nas p. 20, 2 I e 22 que estão aqui.

Também foi retirado o ataque a Afrânio Peixoto das p. 2 e 3, sendo a passagem modificada como vai nesta p. 2 que ficou substituindo portanto as p. 2 e 3 do estudo.

Com isto concordei de bom gosto mas protestei contra a retirada dos critérios do fichário. (p. I3).

O trecho sob censura, agora resgatado, traz uma contribuição de relevo ao debate sobre a ética do trabalho intelectual. Afrânio Peixoto havia reconhecido que, entre as mil quadrinhas reunidas por ele em Trovas populares, 250 eram criação própria. $\mathrm{O}$ expediente teria intenções científicas: mostrar que o folclore possuía uma origem 
culta e que as quadrinhas mais bonitas teriam sido objeto de apropriação pelo povo. As Trovas encontraram a acolhida do público, e versos de Afrânio foram citados como folclóricos sem que ninguém se apercebesse do truque. A crítica de Mário de Andrade é severa. Ele ressalta o estupor provocado pela confissão; trata o caso como "burla" (p. 25) e "abuso da mais ácida ingenuidade" (p. 24); faz questão de denunciar a "leviandade" ao pesquisador estrangeiro; condena o livro como falso. $O$ processo é exemplar daquilo que entende como justo. $\mathrm{O}$ folclore deve ser "verdadeiramente concebido como um processo de conhecimento", não como "uma forma burguesa de prazer" (p. 26)5. Em contraste, reconhece a contribuição de outros pesquisadores, como Amadeu Amaral, Luiz Heitor Corrêa de Azevedo, Luís da Câmara Cascudo; e, apesar de equívocos e insuficiências, de precursores como Couto de Magalhães e Sílvio Romero. O destaque é dado não só a figuras ilustres, mas também ao papel das instituições de pesquisa - a exemplo do Departamento de Cultura, da Sociedade de Etnografia e Folclore e do Serviço do Patrimônio Histórico e Artístico Nacional - e dos periódicos de divulgação. No encadeamento das referências, Mário observa na produção recente uma orientação mais técnica e monográfica, de abandono das grandes obras em proveito de trabalhos especializados.

\section{FADO NEGRO}

Por fim, a parte central do livro compreende um discurso para as festividades do cinquentenário da Abolição e dois artigos de jornal dele derivados. O discurso, ao que tudo indica, não foi proferido. Os festejos coincidiram com a saída de Mário de Andrade da direção do Departamento de Cultura, e não há registro de que tenha tomado parte na solenidade. Por meio da documentação folclórica, ele desejava mostrar que a superstição da cor preta, entranhada no povo, seria a base profunda do preconceito racial. É a parcela espinhosa do livro, que trata de um tema enormemente problemático ainda hoje. A "trágica antinomia" pela qual a cor branca simboliza o Bem e a preta, o Mal, estaria a tal ponto alastrada que, mesmo na sessão solene das associações negras de São Paulo, um orador negro era capaz de imaginar "negros de alma de arminho" (p. 83). Outras expressões análogas, como "negro sim, porém direito", dão indícios do preconceito, expresso aí na adversativa e no suposto contraste. A inexistência de uma linha de cor no Brasil, nos moldes dos Estados Unidos, onde a segregação tinha base legal, estaria demonstrada pelo fato de que "entre nós negro que se ilustre pode galgar qualquer posição", conforme atestam Machado de Assis, "principalíssimo e indiscutido clássico da língua portuguesa” (p. 84), e Nilo Peçanha, que chegou a presidente da República.

Mário de Andrade não embarca na canoa furada da democracia racial; reconhece o preconceito e a desigualdade. Em um dos artigos derivados do discurso - "Linha de cor", saído n’O Estado de S. Paulo, em 29 de março, I939- enumera razões para que um regime de segregação oficial não vigorasse entre nós. Entre elas, os ecos da campanha

5 "Na verdade este 'folclore' que conta em livros e revistas ou canta no rádio e no disco, as anedotas, os costumes curiosos, as superstições pueris, as músicas e os poemas tradicionais do povo, mais se assemelha a um processo de superiorização social das classes burguesas. Ainda não é a procura do conhecimento, a utilidade de uma interpretação legítima e um anseio de simpatia humana" (p. 27). 
abolicionista, a falange de grandes homens negros ou mestiços, o novo "preconceito de liberalismo". Isso nos termos da cultura oficial, pois a ressalva que segue desafina o coro dos contentes: "Mas se formos auscultar a pulsação mais íntima da nossa vida social e familiar, encontraremos entre nós uma linha de cor bastante nítida". E completa: "Me parece indiscutível que o branco no Brasil concebe o negro como um ser inferior" (p. II5).

Não haveria melhor jeito de provar a existência do preconceito, segundo o pesquisador, do que buscar sua documentação folclórica. Daí o inventário de superstições e feitiçarias, na bruxaria europeia como nos catimbós e candomblés do Brasil, atribuindo poder maléfico aos animais de cor preta, e o repertório de provérbios em que a violência contra os negros é incontestável. Como não adoça a realidade amarga, a posição de Mário de Andrade era progressista em seu tempo. Mas conduzir o estudo sobre o negro para o campo do folclore - situando o interesse em termos de "superstição de cor, anterior ao convívio histórico" (p. 89) - soa insuficiente aos olhos de hoje ${ }^{6}$. Não seria justo cobrar que o enfoque nos anos I930 se desse em termos de racismo estrutural, que nomeasse o genocídio e o encarceramento em massa7. E pode-se cogitar que, estando a expressão interditada pela ditadura, falar a partir do folclore fosse um modo de dizer verdades ${ }^{8}$, ainda mais que era, para o autor, um processo de conhecimento e um dado revelador da nossa psicologia social.

No livro, uma abordagem avançada da questão negra, como reparação simbólica, está nos planos para comemorar a Abolição: além de conferências, concurso de peças musicais, concerto sinfônico, exposição iconográfica, reconstrução infantil dos bailados e do cortejo de reis do Congo, sendo coroado o Rei na praça da Sé. Da mesma forma, as sugestões encaminhadas ao ministro Capanema traziam no primeiro item: "organizar uma lista de assuntos concernentes ao problema da escravidão e do abolicionismo e ao negro e sua influência na vida e na civilização brasileiras” (p. 2II)9.

6 Brancos e negros em São Paulo, estudo do começo dos anos I950 coordenado por Roger Bastide e Florestan Fernandes (I959), é nesse aspecto mais contemporâneo nosso. Ali a pesquisa folclórica comparece, mas o interesse está em como o preconceito perpetua elementos da escravidão.

7 O Atlas da violência 20I9, do Instituto de Pesquisa Econômica Aplicada e do Fórum Brasileiro de Segurança Pública, mostra que 75,5\% das vítimas de homicídio no Brasil em 2017 eram negras.

8 Como hoje, aqueles eram tempos sombrios para o país, de censura, arbítrio e violência, e as manifestações culturais estavam com frequência sujeitas a repressão. A censura a práticas afro-brasileiras, como o candomblé e a capoeira, é documentada, e a ela Mário de Andrade faz alusão em “O folclore no Brasil”. No Rio Grande do Norte, as festas de Natal a Reis, o Carnaval e São João eram submetidas a "excessivo controle policial" e "pagamento de taxas de licença estaduais e municipais proibitivas"; e em Pernambuco e na Bahia, os "cultos feiticistas" das populações negras, "sempre perseguidos pela Polícia” (p. 36). Em outro passo, revelando a dimensão política na formação dos acervos, evoca "a coleção de objetos de culto afronegro reunida pela Polícia de Maceió” (p. 43).

9 Para além de Aspectos do folclore brasileiro, a obra de Mário de Andrade é rica de contribuições à expressão e ao entendimento da cultura afro-brasileira. Ver, por exemplo, a tese de Angela Grillo (20I5). 
E, para voltar às "Nótulas" do princípio, penso que um dado dos mais importantes é aquela espécie de "língua de candomblé”

\section{SOBRE O AUTOR}

MARCELO MARANINCHI é doutorando em Literatura Brasileira na Faculdade de Filosofia, Letras e Ciências Humanas da Universidade de São Paulo (FFLCH/USP). Desenvolve como bolsista Fapesp (Proc. n. 20I7/26782-6) a pesquisa "Mário de Andrade: cenografia autoral (I9I7-I922)”.

E-mail: marcelo.maraninchi@usp.br

https://orcid.org/o00o-0003-4963-6I33

\section{REFERÊNCIAS}

ATLAS da violência 20I9. Org.: Instituto de Pesquisa Econômica Aplicada; Fórum Brasileiro de Segurança Pública. Brasília/Rio de Janeiro/São Paulo: Instituto de Pesquisa Econômica Aplicada; Fórum Brasileiro de Segurança Pública. Disponível em: <http://www.ipea.gov.br/portal/images/stories/PDFs/ relatorio_institucional/I90605_atlas_da_violencia_20I9.pdf $\rangle$. Acesso em: 29 nov. 2019.

BALBI, Adrien. Éssai statistique sur le royaume de Portugal et d'Algarve. Paris: Chez Rey et Gravier, I822.

BASTIDE, Roger; FERNANDES, Florestan. Brancos e negros em São Paulo: ensaio sociológico sobre aspectos da formação, manifestações atuais e efeitos do preconceito de cor na sociedade paulistana. São Paulo: Nacional, I959.

FERNANDES, Florestan. Mário de Andrade e o folclore brasileiro. Revista do Arquivo Municipal, São Paulo, n. I06, I946, p. I35-I58. Republicado em: Revista do Instituto de Estudos Brasileiros, n. 36, I994, p. I4I-I58. https://doi.org/Io.Ir606/issn.23I6-90IX.voi36pI4I-I59.

GRILLO, Angela Teodoro. O losango negro na poesia de Mário de Andrade. Tese (Doutorado em Literatura). Programa de Pós-Graduação, Departamento de Letras Clássicas e Vernáculas, Faculdade de Filosofia, Letras e Ciências Humanas, Universidade de São Paulo, 20I5. 239 f.

HANSEN, João Adolfo. Professor de literatura brasileira. Pílula Flip 20I5. Programa em parceria com Canal Arte I. Disponível em: 〈https://youtu.be/3b3EPABlUDo >. Acesso em: 29 nov. 2019.

Io A expressão é de João Adolfo Hansen (20I5), referindo-se à rapsódia modernista: "Macunaíma era escrito em língua de candomblé. E o que eu acho legal no Mário é justamente isso. Escrever em língua de negro. Porque num país como esse todos nós somos negros, não é isso? Eu pelo menos faço questão de ser negro". 